Volume 5 No. 1

Mei 2017

\title{
Analisis Faktor - Faktor Yang Mempengaruhi Keputusan Pembelian di Forum Jual Beli Online Studi Pada Mahasiswa STMIK GICI Batam
}

\author{
Joko Setiawan \\ Akademi Akuntansi Permata Harapan Batam \\ Komp. Perumahan Graha Nusa Permai Blok C 8 No. 07-09 \\ Email : awwansetyawan@gmail.com
}

\begin{abstract}
ABSTRAK
Ditinjau dari tujuannya, penelitian ini termasuk dalam penelitian dasar karena penelitian ini merupakan penelitian di bidang akademik yang mengarah pada pengembangan teori dan tidak menekankan pada pemecahan masalah. Jika ditinjau dari permasalahannya, penelitian ini termasuk dalam penelitian kausal-komparatif (causal comparative research), karena penelitian ini meneliti pengaruh antara Keputusan Pembelian (Y) dengan Trust (X1), ease of use (X2), Information Quality (X3), Website Quality (X4), dan Product Quality (X5).
\end{abstract}

Kata kunci: Keputusan pembelian, Trust, ease of use, iformation quality, website quality, projrct quality

\section{Latar Belakang Masalah}

Dewasa ini, e-commerce lebih dari sekedar membeli dan menjual produk secara online. Ecommerce meliputi seluruh proses dari pengembangan, pemasaran, penjualan, pengiriman, pelayanan, dan pembayaran para pelanggan, dengan dukungan dari jaringan para mitra bisnis di seluruh dunia. Sistem e-commerce sangat bergantung pada sumber daya internet dan banyak teknologi informasi lainnya untuk mendukung setiap proses ini. Selain alasan untuk pengembangan bisnis, penggunaan sumber daya internet dikarenakan jumlah potensial dari pengguna internet di seluruh dunia yang dari tahun ke tahun mengalami peningkatan.
Perubahan dramatis dalam bidang teknologi telah merubah cara hidup konsumen, cara belanja, dan berinteraksi dengan yang lainnya. Meningkatnya jumlah pengguna internet, telah menarik berbagai usaha bisnis untuk memasarkan produknya melalui internet. Internet dapat menyediakan channel untuk memasarkan produk atau jasa secara online. Salah satu situs internet di Indonesia yang menerapkan konsep e-commerce adalah Kaskus. Website Kaskus sangat ramai dikunjungi oleh web browser baik Indonesi maupun luar negeri. Kaskus terkenal karena menyediakan berbagai macam forum, termasuk forum jual beli dengan menyediakan pasar virtual untuk bertransaksi jual beli secara
JURSIMA

Jurnal Sistem Informasi dan Manajemen https://ejournal.giciku.ac.id/ STMIK GICI 
Volume 5 No. 1

Mei 2017

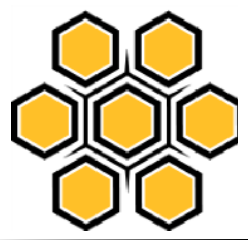

online. Melalui internet, Kaskus menjual produknya yang berupa apparel (pakaian jadi), handphone, mobil, dan lain sebagainya.

Kaskus adalah situs forum komunitas maya terbesar di Indonesia. Kaskus lahir pada tanggal 6 November 2000 oleh tiga pemuda asal Indonesia yang sedang melanjutkan studi di Seattle, Amerika Serikat. Situs ini dikelola oleh PT. Darta Media Indonesia. Kaskus, yang merupakan singkatan dari Kasak Kusuk, bermula dari sekedar hobi dari komunitas kecil yang kemudian berkembang hingga saat ini. Kaskus dikunjungi sedikitnya oleh 500.000 orang, dengan jumlah page view melebihi 3.500 .000 setiap harinya. Anggotanya, yang berjumlah lebih dari 900.000, tidak hanya berdomisili dari Indonesia namun tersebar juga hingga negara lainnya. Pengguna Kaskus umumnya berasal dari kalangan remaja hingga orang dewasa. Berdasar data Alexa, pada tahun 2009 Kaskus menempati urutan 377 di dunia untuk kategori situs populer. Kemudian pada bulan April 2010, peringkat Kaskus naik menjadi berada di peringkat 313 dunia dan menduduki peringkat 6 situs yang paling banyak dikunjungi di Indonesia (www.alexa.com).

Dengan posisi tersebut, Kaskus sudah berstatus sebagai situs Indonesia yang paling populer di dunia mengalahkan situs-situs Indonesia lainnya. Per November 2009, jumlah anggota dari situs ini telah mencapai 1.194.697 orang.

Sebagai sebuah situs populer di dunia, Kaskus banyak mendapat penghargaan. Diantaranya pada bulan Agustus 2005, PC Magazine

JURSIMA

Jurnal Sistem Informasi dan Manajemen
Indonesia memberikan penghargaan kepada situs Kaskus sebagai situs terbaik dan komunitas terbesar, kemudian Kaskus terpilih kembali sebagai website terbaik pilihan pembaca PC Magazine pada 2006. Penghargaan yang diterima oleh Kaskus ini dibuktikan dengan jumlah pengunjung situs per harinya sekitar 600 ribu orang, dengan jumlah page view melebihi 15.000.000 setiap harinya. Data tentang situs Kaskus disajikan dalam table 1.1 berikut ini (www.alexa.com):

\section{Rumusan Masalah}

1. Apakah terdapat pengaruh kepercayaan (trust) terhadap keputusan pembelian online (online purchase decision)?

2. Apakah terdapat pengaruh kemudahaan (ease of use) terhadap keputusan pembelian online (online purchase decision)?

3. Apakah terdapat pengaruh kualitas informasi (information quality) terhadap keputusan pembelian online (online purchase decision)?

4. Apakah terdapat pengaruh Kualitas Website terhadap keputusan pembelian online?

5. Apakah terdapat pengaruh Kualitas Produk terhadap keputusan pembelian online?

\section{Tujuan dan Manfaat Penelitian}

1. Untuk menganalisis pengaruh kepercayaan (trust) terhadap keputusan pembelian online (online purchase decision).

2. Untuk menganalisis pengaruh kemudahan (ease of use) terhadap keputusan pembelian 
Volume 5 No. 1

Mei 2017

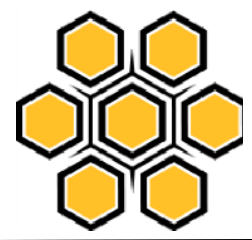

online (online purchase decision).

3. Untuk menganalisis pengaruh kualitas informasi (information Quality) terhadap keputusan pembelian online (online purchase decision).

4. Untuk Menganalisis pengaruh Kualitas Website terhadap keputusan pembelian online.

5. Untuk Menganalisis pengaruh Kualitas Produk terhadap keputusan pembelian online.

\section{KERANGKA TEORETIS DAN PERUMUSAN HIPOTESIS}

Hubungan Keptusan Pembelian (Y) dengan Trust (X1), ease of use (X2), Information Quality (X3), Website Quality (X4), dan Product Quality (X5)

Keputusan pembelian ulang dapat didefinisikan sebagai serangkaian unsurunsur yang mencerminkan keputusan konsumen dalam membeli, merupakan tahap dimana konsumen dihadapkan suatu pilihan untuk melakukan pembelian atau tidak. (Kotler, 1995)

Jia, Shen "User Acceptance of Social Shopping Sites: A Research Proposal" meneliti pengaruh perceive usefulness, perceived ease of use, tendency to social comparison, dan trust terhadap melakukan keputusan pembelian (buying decision). Didapat hasil bahwa kepercayaan (trust) berpengaruh signifikan positif terhadap melakukan pembelian sebuah produk. Dapat diartikan bahwa disini variable kepercayaan (trust) dapat dijadikan salah satu variabel independen, karena berperan besar dalam kaitannya dengan online shopping, untuk di uji kembali.

Terro Pikkarainen, et al. (2004) meneliti faktor-faktor yang mempengaruhi penerimaan Sistem online banking oleh pelanggan pada perusahaan perbankan di Finlandia. Variabel yang digunakan adalah perceived usefullness, preceived ease of use, perceived enjoyment, security dan privacy, internet connection, dan amount of information. Hasil penelitian menunjukkan bahwa preceived ease of use, memiliki pengaruh terhadap penerimaan sistem online banking. Dapat diartikan bahwa disini variabel kemudahan (ease of use) dapat dijadikan sebagai variabel independendengan melakukan beberapa penyesuaian untuk setting penelitian online shopping.

Park, C.H dan Kim, Y.G. (2003) "Identifying Key Factors Affecting Consumer Purchase Behaviour In An Online Shopping Context" meneliti tentang hubungan antara bermacam karakteristik online shopping dan perilaku pembelian konsumen. Variabel untuk karakteristik online shopping yaitu: 1) kualitas informasi, 2) kualitas user interface, 3) persepsi keamanan, 4) site awareness, 5) kepuasan informasi, 6) relational benefits, 7) site commitment.

Hasil penelitian menunjukkan bahwa kualitas informasi, kualitas user interface, persepsi keamanan, berpengaruh terhadap kepuasan informasi dan relational benefits. Hasil penelitian lainnya adalah kepuasan informasi dan relational benefits masing-masing berpengaruh terhadap site commitment dan 
Volume 5 No. 1

Mei 2017

perilaku pembelian aktual. Dapat diartikan bahwa disini variabel kualitas informasi (Information Quality) dapat dijadikan salah satu variabel independen untuk setting penelitian online shopping.

\section{Hubungan Kepercayaan (Trust) dengan Keputusan Pembelian Online}

Untuk dapat mempertahankan hubungan jangka panjang dengan para pembelinya, pihak penjual online perlu menganut konsep kepuasan pelanggan (costumer satisfaction). Agar dapat bertahan hidup dalam era online shopping, pihak penjual online harus mempunyai pelanggan loyal (customer loyality) yang percaya terhadap ekselensi jasa online shopping. Seiring maraknya kejahatan internet seperti misalnya pembobolan kartu kredit dan penipuan, faktor kepercayaan (trust) menjadi hal yang sangat penting dalam transaksi online shopping. Konsep kepercayaan ini berarti bahwa pembeli percaya terhadap keandalan pihak penjual online yang dapat menjamin keamanan bertransaksi online. Keamanan berarti bahwa transaksi penjualan online dapat dipercaya. Kepercayaan pembeli terhadap website online shopping terletak pada popularitas website online shopping tersebut. Semakin popularitas suatu website, maka pembeli lebih yakin dan percaya terhadap reliabilitas website tersebut. Selanjutnya, kepercayaan pembeli terhadap penjual online juga terkait dengan keandalan penjual online dalam menjamin keamanan bertransaksi, meyakinkan transaksi akan diproses setelah pembayaran dilakukan oleh pembeli, dan kesalahan penagihan pada kartu kredit atas "pembelian berulang". Keandalan ini terkait dengan keberadaan penjual online. Semakin berkembangnya teknologi, semakin berkembang pula modus penipuan berbasis teknologi pada online shopping. Pada situs-situs online shopping, sedikit penjual online fiktif yang memasarkan produk fiktif juga.

\section{Hubungan Kemudahan (Easy Of Used) dengan Keputusan Pembelian Online.}

Davis (1989) mendefinisikan kemudahan (ease of use) sebagai suatu tingkatan dimana seseorang percaya bahwa suatu teknologi dapat dengan mudah digunakan. Menurut Goodwin (1987); Silver (1988); dalam Adam, et al. (1992), intensitas penggunaan dan interaksi antara user dengan sistem juga dapat menunjukkan kemudahan. Suatu sistem online yang lebih sering digunakan menunjukkan bahwa sistem tersebut lebih dikenal, lebih mudah dioperasikan dan lebih mudah digunakan oleh user.

\section{Hubungan Kualitas Informasi (Information Quality) dengan Keputusan Pembelian Online.}

Informasi yang disajikan pada online shop sebaiknya mencakup informasi berkaitan dengan produk dan jasa yang ada pada online shopping. Informasi tersebut sebaiknya berguna dan relevan dalam memprediksi kualitas dan kegunaan produk atau jasa.

Untuk memuaskan kebutuhan informasi konsumen/pembeli online, informasi produk dan jasa harus up- 
Volume 5 No. 1

Mei 2017

to-date, membantu pembeli online dalam membuat keputusan, konsisten, dan mudah dipahami. Informasi produk adalah informasi tentang karakteristik suatu produk (www.wikipedia.com). Informasi produk pada online shopping mencakup informasi atribut suatu produk, rekomendasi dari para konsumen, laporan evaluasi, dll.

\section{Hubungan Kualitas Website dengan Keputusan Pembelian Online.}

Sebuah Web Site harus dapat memberikan pelayanan kepada pelanggan dan dapat dijadikan sebagai faktor persuasif daripada hanya dibentuk sebagai brosur online atau sebuah katalog mengenai suatu produk yang ingin ditawarkan.Mutu Web Site meliputi dua hal, dapat dilihat dari jaminan dari pihak ketiga (Third-party assurance seal) dan bentuk atau design dari Web Site itu sendiri. Dalam e-commerece, pelanggan jarang sekali bertemu dengan salesman untuk bertransaksi, untuk itu kepercayaan harus ditempatkan secara langsung dalam website eretailer. Dalam penjualan secara tradisional, pelanggan dapat langsung menilai perusahaan dari petunjukpetunjuk fisik yang ada seperti besar kecilnya perusahaan, kebersihan, seragam sales, dan lain sebagainya. Lebih lanjut, penilaian dapat dilihat dari salesman itu sendiri, pengetahuannya tentang produk, kemampuannya menjal dan bahkan karakter personalnya seperti kejujuran, familiar atau tidaknya dengan pelanggan, pengalamannya dalam menjual produk. Dalam internet petunjuk-petunjuk ini dan hubungan dengan salesman tidak dapat terpenuhi dengan baik (Gefen, 2002).

\section{Pengaruh Kualitas Produk Terhadap Keputusan Pembelian Online.}

Begitu pentingnya kualitas pernah digambarkan sebagai satu-satunya kekuatan terpenting yang membawa pertumbuhan ekonomi perusahaan ke pasar internasional (Feigenbaum,1982)., setidaknya ada 3 hal yang menyebabkan perusahaan mengarah ke penekanan kualitas produk, dalam bersaing di pasar yaitu sejak perang dunia ke-2, teknologi telah memungkinkan sedikit orang untuk menghasilkan suatu produk berkualitas tinggi dan dengan harga bersaing, kemudian yang kedua adalah kemajuan pesat dalam bidang telekomunikasi dan transportasi telah memungkinkan pemindahan data dan produk ke manapun dengan sangat cepat, dan yang ketiga adalah hambatanhambatan melakukan perdagangan ke seluruh dunia telah berkurang, sehingga memungkinkan untukmenjalankan bisnis di manapun dan kapanpun. (Cortada,1996). https://ejournal.giciku.ac.id/ STMIK GICI 
Kerangka Pemikiran Teoritis Gambar 2.1 Kerangka Pemikiran Teoritis

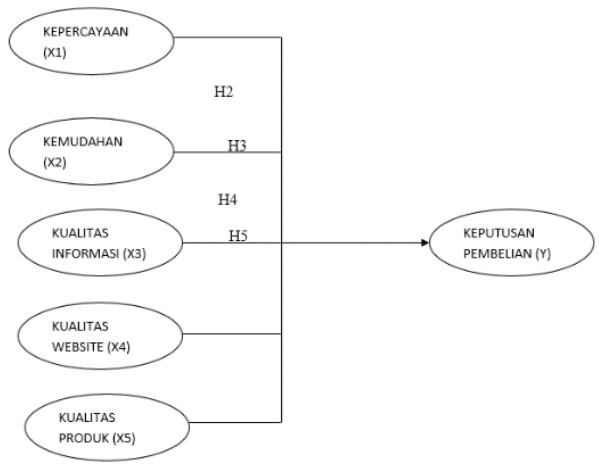

Sumber: Penelitian terdahulu yang dikembangkan

\section{Hipotesis Penelitian}

H1 : kepercayaan (easy of used), berpengaruh secara positif terhadap keputusan pembelian online.

H2 : Kemudahan (ease of use), berpengaruh secara positif terhadap keputusan pembelian online.

H3 : Kualitas Informasi (information Quality), berpengaruh secara positif terhadap keputusan pembelian online.

H4 : Kualitas Website berpengaruh secara positif terhadap keputusan pembelian online.

H5 : Kualitas Produk berpengaruh secara positif terhadap keputusan pembelian online.

\section{METODE PENELITIAN Obyek Penelitian \\ Populasi}

Populasi adalah wilayah generalisasi yang terdiri atas obyek atau subyek yang mempunyai kualitas dan karakteristik tertentu yang ditetapkan oleh peneliti untuk

JURSIMA

Jurnal Sistem Informasi dan Manajemen dipelajari dan kemudian ditarik kesimpulannya (Sugiyono, 1999).

Populasi pada penelitian ini adalah Mahasiswa STMIK GICI Batam yang menjadi anggota Kaskus ataupun non anggota yang pernah melakukan pembelian secara online pada Forum Jual Beli (FJB) Kaskus.

\section{Sampel}

Sampel merupakan bagian dari jumlah dan karakteristik yang dimiliki oleh populasi tersebut (Sugiyono, 1999). Dalam menentukan data yang akan diteliti, teknik pengambilan sampling yang digunakan adalah dengan non probability sampling yaitu teknik sampling yang tidak memberikan kesempatan sama bagi setiap unsur atau anggota populasi untuk dijadikan sampel. Responden yang dipilih adalah Mahasiswa STMIK GICI Batam anggota Kaskus ataupun non anggota yang berminat untuk membeli online pada Forum Jual Beli (FJB) Kaskus sebanyak 200 responden.

\section{Teknik Pengumpulan Data}

Dalam melakukan penelitian, data yang dikumpulkan akan digunakan untuk memecahkan masalah yang ada sehingga data-data tersebut harus benar-benar dapat dipercaya dan akurat. Data yang digunakan dalam penelitian ini diperoleh melalui metode kuesioner yaitu teknik pengumpulan data yang dilakukan dengan cara memberi kuesioner atau seperangkat pertanyaan atau pernyataan tertulis kepada responden (Sugiyono, 2001). Dalam kuesioner ini nantinya terdapat rancangan pertanyaan yang 
ISSN 2338-1523

E-ISSN 2541-576X

Volume 5 No. 1

Mei 2017

HasilUji Kepercayaan terhadap Keputusan pembelian online

secara logis berhubungan dengan masalah penelitian dan tiap pertanyaan merupakan jawabanjawaban yang mempunyai makna dalam menguji hipotesa. Dibandingkan dengan interview guide daftar pertanyaan atau kuesioner lebih terperinci dan lengkap.

\section{ANALISIS DAN PEMBAHASAN Uji Hipotesis}

Pengujian

hipotesis menggunakan regresi berganda yaitu digunakan untuk menganalisis hubungan antara kepercayaan, kemudahan penggunaan, kualitas informasi, kualitas website,dan kualitas produk.

\section{Uji F}

Hasil uji F pada tabel 5.4 menunjukkan angka signifikan sebesar 0,000. Jadi, dengan tingkat signifikan 0,000 lebih kecil dari 0,05, maka model regresi dapat digunakan untuk memprediksi Keputusan Pembelian Online.

\begin{tabular}{|c|c|}
\hline & \\
\hline $\begin{array}{l}\text { Model } \\
\text { F }\end{array}$ & Sig. \\
\hline $\begin{array}{l}\text { Regression } \\
17,055\end{array}$ & $0,000^{\mathrm{a}}$ \\
\hline
\end{tabular}

\section{Uji t}

Berdasarkan hasil uji t pada tabel diatas menunjukkan signifikan kepercayaan adalah 0,000 atau probabilitas berada dibawah 0,05 . Oleh karena itu $\mathrm{H} 1_{0}$ ditolak artinya terdapat pengaruh kepercayaan terhadap keputusan pembelian online.

\begin{tabular}{ccc}
\hline $\begin{array}{c}\text { Variabel } \\
\text { Unstandardized } \\
\text { Coefficients }\end{array}$ & $\begin{array}{c}\text { Standardized } \\
\text { Coefficients }\end{array}$ \\
Sig. & \multicolumn{2}{c}{ Std. } \\
& B & Error \\
\hline 1. Konstanta & 2,268 & 0,904 \\
& & 2,509 \\
0,013 & & \\
Kepercayaan & 0,195 & 0,053 \\
0,145 & & 3,707 \\
0,000 & &
\end{tabular}

Sumber: Data primer diolah (2017)

Berdasarkan hasil uji t tabel
5.5 menunjukkan signifikan
kemudahan penggunaan adalah
0,045 atau probabilitas dibawah
0,05. Oleh karena itu $\mathrm{H} 2_{0}$ ditolak
artinya terdapat pengaruh
kemudahan penggunaan terhadap
keputusan pembelian online.

HasilUji Kemudahan penggunaan terhadap keputusan pembelian onliune

Variabel

Unstandardized Standardized Coefficients

Sig. Coefficients $\quad \mathrm{t}$

\begin{tabular}{clc} 
& \multicolumn{2}{c}{ Std. } \\
& B & Error \\
\hline 1. Konstanta & 2,268 & 0,904 \\
& & 2,509 \\
0,013 & & \\
Kemudahan & 0,054 & 0,027 \\
0,060 & & 2,027 \\
0,045 & & \\
Penggunaan & & \\
\hline
\end{tabular}


ISSN 2338-1523

E-ISSN 2541-576X

Volume 5 No. 1

Mei 2017

Sumber: Data primer diolah (2017)

Berdasarkan hasil uji t tabel diatas menunjukkan signifikan kualitas informasi adalah 0,041 atau probabilitas diatas 0,05 . Oleh karena itu $\mathrm{H} 3_{0}$ ditolak artinya terdapat pengaruh kualitas informasi terhadap keputusan pembelian online.

Hasil Uji Kualitas Informasi terhadap Keputusan pembelian online

\begin{tabular}{llc}
\hline $\begin{array}{l}\text { Variabel } \\
\text { Unstandardized } \\
\text { Coefficients }\end{array}$ & $\begin{array}{c}\text { Standardized } \\
\text { Coefficients }\end{array}$ \\
Sig. & \multicolumn{2}{c}{ Std. } \\
& \multicolumn{3}{c}{ Error } \\
\hline 1. Konstanta & 2,268 & 0,904 \\
& & 2,509 \\
0,013 & & \\
Kualitas & 0,053 & 0,039 \\
0,042 & & 1,378 \\
0,041 & & \\
Informasi & &
\end{tabular}

Sumber: Data primer diolah (2017) Berdasarkan hasil uji t tabel diatas menunjukkan signifikan kualitas website adalah 0,005 atau probabilitas dibawah 0,05. Oleh karena itu $\mathrm{H}_{4}$ ditolak artinya terdapat pengaruh kualitas website terhadap keputusan pembelian online.

Hasil Uji Kualitas website terhadap keputusan pembelian online

\begin{tabular}{|c|c|}
\hline \multicolumn{2}{|l|}{ Variabel } \\
\hline Unstandardized & $\begin{array}{l}\text { Standardized } \\
\text { Coefficients }\end{array}$ \\
\hline Coefficients & $\mathrm{t}$ \\
\hline
\end{tabular}

JURSIMA

Jurnal Sistem Informasi dan Manajemen

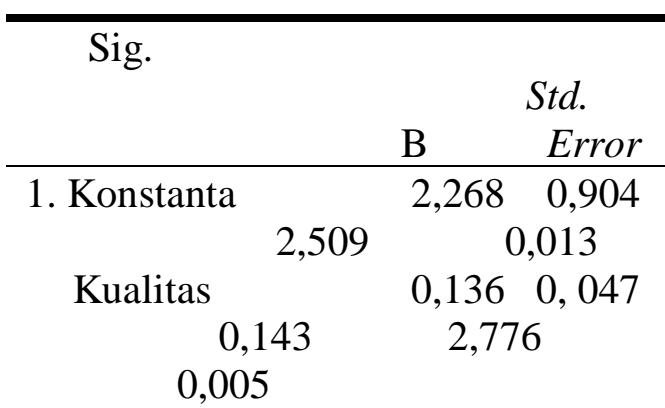

website

Sumber: Data primer diolah (2017) Berdasarkan hasil uji $\mathrm{t}$ tabel 5.8 menunjukkan signifikan kualitas produk adalah 0,000 atau probabilitas dibawah 0,05 . Oleh karena itu $\mathrm{H} 50$ ditolak artinya terdapat pengaruh kualitas produk terhadap keputusan pembelian online.

HasilUji kualitas produk terhadap keputusan pembelian online

\begin{tabular}{rc}
\hline Variabel & \\
Unstandardized & $\begin{array}{c}\text { Standardized } \\
\text { Coefficients }\end{array}$ \\
Coefficients & $\mathrm{t}$
\end{tabular}

Sig.

Std.

\begin{tabular}{|c|c|c|c|}
\hline \multirow{3}{*}{\multicolumn{2}{|c|}{ 1. Konstanta }} & B & Error \\
\hline & & 2,268 & 0,904 \\
\hline & & 2,509 & 0,013 \\
\hline Kualitas & & 1,970 & 0 \\
\hline $\begin{array}{l}079 \\
0,000\end{array}$ & 0,840 & & 2,859 \\
\hline
\end{tabular}

Produk

Sumber: Data primer diolah (2017) Uji R $\mathbf{R}^{2}$

Berdasarkan hasil uji $\mathrm{R}^{2}$ pada tabel 5.9 diperoleh nilai $\mathrm{R}^{2}$ sebesar 0,901 berarti $90,1 \%$ variable keputusan pembelian online dijelaskan oleh kepercayaan, kemudahan penggunaan, kualitas informasi,kualitas website dan 
Volume 5 No. 1

Mei 2017

kualitas produk sebagai variabel independent. Sedangkan sisanya $(100 \%-90,1 \%=9,9 \%)$ dijelaskan oleh sebab-sebab lain diluar model. Sedangkan nilai SEE (Standard Error of Estimate) sebesar 1,17321 berarti tingkat kesalahan penafsiran dari regresi adalah sebesar 1, 17321.

\section{Hasil Uji R ${ }^{2}$}

\begin{tabular}{ll}
\hline Model & SEE \\
R Square & \\
\hline 1 & \\
0,901 & \\
\multicolumn{1}{c}{1,173} & \\
\hline
\end{tabular}

Sumber: Data primer diolah (2017)

KESIMPULAN,

KETERBATASAN DAN

REKOMENDASI

\section{Kesimpulan}

Dalam penelitian ini terdapat beberapa kesimpulan antara lain:

a. Hasil pengujian diperoleh bahwa Kepercayaan signifikan terhadap Keputusan pembeilian secara online .Hasil pengujian ini mendukung penelitian terdahulu tentang kepercayaan (Trust) (Gefen, Karahanna, et al, 2003; Gefen dan Straub, 2003; dan Jia, Shen, undated). Hal ini terjadi karena factor kepercayaan menunjukkan bahwa pembeli percaya terhadap keandalan pihak penjual online yang dapat menjamin keamanan bertransaksi secara online.

b. Hasil pengujian diperoleh bahwa Kemudahan signifikan terhadap Keputusan pembeilian secara online. Hasil pengujian ini

JURSIMA

Jurnal Sistem Informasi dan Manajemen konsisten dengan hasil tori dan penelitian tedahulu mengenai kemudahan (Davis, 1989; Venkatesh dan Davis, 2000; Pikkarainen, et al., 2004). Hal tersebut dapat disimpulkan bahwa kemudahan akan mengurangi usaha (baik waktu dan tenaga) seseorang di dalam mempelajari system online.

c. Hasil pengujian diperoleh bahwa Kualitas Informasi signifikan terhadap Keputusan pembeilian secara online. Hasil pengujian ini konsisten dengan hasil teori dan penelitian tedahulu mengenai kualitas informasi(Park, C.H dan Kim, Y.G.,2003). Hal tersebut dapat disimpulkan bahwa semakin berkualitas informasi yang diberikan kepada pembeli online, maka akan semakin tinggi minat pembeli online untuk membeli produk tersebut.

d. Hasil pengujian diperoleh bahwa Kualitas Website signifikan terhadap Keputusan pembeilian secara online. Hasil pengujian ini konsisten dengan hasil teori dan penelitian tedahulu mengenai kualitas Website (Gefen, 2002). Dengan demikian dapat disimpulkan Sebuah Web Site harus dapat memberikan pelayanan kepada pelanggan dan dapat dijadikan sebagai faktor persuasif daripada hanya dibentuk sebagai brosur online atau sebuah katalog mengenai suatu produk yang ingin ditawarkan.

e. Hasil pengujian diperoleh bahwa Kualitas Produk signifikan terhadap Keputusan pembeilian secara online. Hasil pengujian 
Volume 5 No. 1

Mei 2017

ini konsisten dengan hasil teori atau penelitian tedahulu mengenai kualitas Produk(Cortada,1996). Hal ini menunjukkan apapun media dalam melakukan perdagangan kualitas produk menjadi factor yang cukup berpengaruh terhadap keputusan pembelian.

\section{Keterbatasan}

Dalam penelitian ini nilai $\mathrm{R}^{2}$ yang diperoleh sebesar 0,901 berarti $90,1 \% \quad$ variable keputusan pembelian online dapat dijelaskan oleh kepercayaan, kemudahan penggunaan, kualitas informasi,kualitas website dan kualitas produk sebagai variabel bebas. Sedangkan sisanya $\quad(100 \%-90,1 \%=9,9 \%)$ dijelaskan oleh factor-faktor lain diluar model.

\section{Rekomendasi}

Berdasarkan hasil penelitian dan kesimpulan diatas, penulis ingin memberikan beberapa rekomendasi sebagai berikut:

a. Dalam penelitian ini nilai $\mathrm{R}^{2}$ yang diperoleh sebesar 0,901 berarti $90,1 \% \quad$ variable keputusan pembelian online dapat dijelaskan oleh kepercayaan, kemudahan penggunaan, kualitas informasi,kualitas website dan kualitas produk sebagai variabel bebas. Sedangkan sisanya $\quad(100 \%-90,1 \%=9,9 \%)$ dijelaskan oleh factor-faktor lain maka direkomendasikan juga untuk meneliti variabel lainnya seperti perceived risk sebagai variabel independen ( Bove \& Johnson, 2006)

b. Penelitian ini dapat juga diteliti pada seluruh penyedia jasa belanja online yang ada diluar kota Batam dengan lebih memfokuskan pada sejauh mana minat pembeli maupun pelanggan dalam memutuskan untuk berbelanja secara online dengan beberapa factor diantaranya adalah kepercayaan,kemudahan,kualit as informasi, kualitas website dan kualitas produk yang mempengaruhinya.

\section{DAFTAR PUSTAKA}

Beaver, K. (2002). Information security issues that healthcare management must

understand. Journal of Healthcare Information Management, 17(1), 46-49.

Buecker, A., Ferrell, M., \& Whitmore, J. (2005). Patterns: IT systems management and security. New York: IBM Corp.

Chang, H., Han, G., Weng, A., \& Qin, G. (2006). Authentication and network security. Journal of Technology and Business, 14.

Cheung, C. M. K., \& Lee, M. K. O. (2005). Research framework for consumer satisfaction with internet shopping. European Conference on Information Systems, 9. 
Volume 5 No. 1

Mei 2017

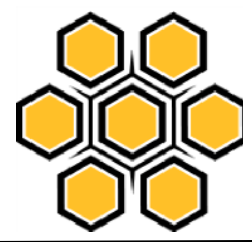

Corbitt, B. J. (2003). Globalization, culture and ebusiness. Hershey: Idea Group Inc.

Fink, D., Huegle, T., \& Dortschy, M. (2006). A model of information security governance for e-business. Hershey: Idea Group Inc.

Fong, B. C. M., Fong, A. C. M., \& Chan, C. H. Y. (2000). Managing the planning process. EBusiness Project Management, 4.

Fuller, E. (2003). Common sense security for common businesses. Colorado: Security Horizon, Inc.

Ghozali, I. (2001). Aplikasi analisis multivariate dengan program SPSS. Semarang: Badan Penerbitan Universitas Diponegoro.

Hair, J. F., Black, W. C., Babin, B. R., Anderson, R. E. \& Tatham, R. L. (2006). Multivariate data analysis, 6th Edition. New Jersey: Prentice Hall International Inc.

Harian Batam Pos. (2007). Quo-vadis pariwisata Batam. Pemerhati Pariwisata Batam, p. B22.

Hauswirth, M., Jazayeri, M., \& Schneider, M. (2000). A phase model for e-commerce business models and its application to security assessment. Vienna: Technical University of Vienna.

Ho, C. F., \& Wu, W. H. (1999). Antecedents of customer satisfaction on the internet: An empirical study of online shopping. Proceedings of the 32nd Hawaii
International Conference on System Sciences, 5.

Horsti, A., Tuunainen, V. K., \& Tolonen, J. (2005). Evaluation of electronic business model success: Survey among leading finish companies. Proceedings of the 38th Hawaii International Conference on System Sciences, 1-5.

Indriantoro, N., \& Supomo, B. (1999). Metodologi penelitian bisnis untuk akuntansi dan manajemen. Yogyakarta: BPFE.

Kabay, M. E. (2001). The net present value of information security: A paradigm shift for infosec and e-commerce. Journal of e-Business and Information Technology, 2(1), 14-22.

Katos, V. (2000). Dealing with internet risks. Journal of Internet Security, 3(1), 4.

Kim, J., Lee, J., Han, K., \& Lee, M. (2002). Businesses as buildings: Metrics for the architectural quality of internet businesses. Information Systems Research, 13(3), 241-250

Kinczkowski, L. M. Ph. D. (2003). E-commerce security: Business continuity planning. Mass: Information Systems Audit and Control Association, Inc.

Kleinwachter, W. (2004). Internet co-governance towards a multilayer multiplayer mechanism of conclusion, coordination and cooperation. Informal Consultation of the Working Group on Internet Governance, 2, 1. 
Volume 5 No. 1

Mei 2017

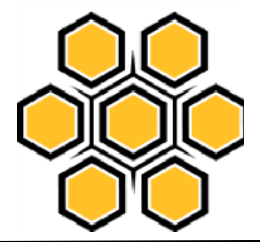

Korzyk, A. D. Sr. (1999).

Towards security of integrated enterprise systems management. Journal of Information Technology Management, 6-7.

Malley, J. R., \& Matheson, L. A. (2002). New directions for research in electronic data interchange (EDI). Journal of Information Technology Management, 8, (3-4), 36.

Mohammed, M., Mohyuddin, S., Mansoor, M. A., \& Lohana, M. K. (2001). Information systems security and control. Information Systems Security and Control, 3-9.

Morgan, R. (2006). Information security for small businesses. Journal of Information Technology Management, 1.

National Information Infrastructure Task Force. (1996). Information systems security board. The National Security Telecommunications Advisory Committee, p. B11.

Ou, X. J., Choon, L. S., \& Banerjee, R. (2007). What is hampering online shopping in China?. Journal of Information Technology Management, 18, (1), 28-29.

Paliouras, V., \& Hellas, S. S. A. (2001). The need of email content security. Journal of Internet Security, 3(1), 5 .

Price Water House Coopers. (1999). E-security cyber thieves and vandals in the internet age. US: Time, Inc.
Purnama, K., Sherly, E., Selpiyani, Tati, R., Elfrida, S., Wayan, S., Kun, A., Yanti, A., \& Wella, R. et al. (2008). Makalah sistem informasi manajemen tentang e-ticketing. Jurnal Sistem Informasi Manajemen, 1-2.

Ramadorai, S. (2008, December 03). Internet governance forum 2008. The World Business Organization, p. B8.

Shi, D., \& Daniels, R. L. (2003). A survey of manufacturing flexibility: Implications for ebusiness flexibility. IBM systems journal, 42(3), 418.

Sohmen, P. (2001). Taming the dragon: China's efforts to regulate the internet. Stanford Journal of East Asian Affairs, 1, 19.

Stansfield, M., \& Grant, K. (2003). An investivigation into issues influencing the use of the internet and electronic commerce among small-medium sized enterprises. Journal of Electronic Commerce Research, 4(1), 15.

The Alliance for Enterprise Security Risk Management. (2005). Convergent security risks in physical security systems and IT infrastructures. Alexandria: AESRM Member Organizations.

Vasiu, L., Mackay, D., \& Warren, M. (2004). The tridimensional role of information security in e-business: A managerial perspective. Journal of Information Technology Management, 2-4.

Wikipedia. (2009). Retrieved February 11, 2009, from 
ISSN 2338-1523

E-ISSN 2541-576X

Volume 5 No. 1

Mei 2017

http://id.wikipedia.org/wiki/Kota_Ba tam

Whitmore, J. (1998). 21st national information systems security conference 1998. IBM Corporation, p. B1.

World Tourism Organization. (2006). Retrieved February 11, 2009, from http://www.worldtourism.org/facts/menu.html.

Yu, J. H., \& Le, T. K. (2001). Internet and network security. Journal of Industrial Technology, 17(1), 2-6.

Zhu, D. (2002). Security control in inter-bank fund transfer. Journal of Electronic Commerce Research, 3(1), 15. 